Tipping and Service Quality: A Within-Subjects Analysis

\author{
Michael Lynn and Michael J. Sturman* \\ Cornell University
}

Journal of Tourism and Hospitality Research, 34 (2), 269-275.

* Michael Lynn is a professor of consumer behavior and Michael Sturman is an associate professor of human resources at the School of Hotel Administration, Cornell University, Ithaca, NY 14853-6902. The lead author may be contacted via phone at (607)255-8271, via fax at (607) 255-1355, or via e-mail at WML3@Cornell.edu. The authors want to thank Dr. Edward Blair for help in collecting the data in this study. 


\title{
Tipping and Service Quality: A Within-Subjects Analysis
}

\begin{abstract}
Restaurant tips are supposed to be an incentive/reward for the delivery of good service. In order for tipping to serve this function, consumers must leave larger tips in response to better service. Numerous studies have found a relationship between evaluations of service and tip size, but these studies have involved between-subjects, correlational designs that mean the observed relationships could be due to extraversion, friendliness, generosity or other stable dispositional differences between tippers that affect both service ratings and tip sizes. The current study attempts to rule out these alternative explanations by examining the tipping behavior of 51 people across multiple dining occasions. Results indicate that tip sizes are reliably correlated with service ratings after controlling for the identity of the tipper and, therefore, all potential stable dispositional difference confounds. The theoretical and practical implications of this finding are discussed.
\end{abstract}

Keywords: tipping, service quality, equity, incentive, reward 
Tipping and Service Quality: A Within-Subject Analysis

Restaurant and bar patrons often leave voluntary payments of money (or tips) to the waiters and waitresses who have served them. These tips, which amount to about $\$ 42$ billion a year in the United States alone (Azar, 2007), are supposed to be an incentive/reward for good service. The highly customized nature of restaurant services makes it difficult for management to monitor and control the quality of waiters' and waitresses' efforts to serve their customers, so these quality control tasks are left up to customers via the institution of tipping. In fact, economists have theorized that tipping exists because it is the most efficient way to provide service workers with performance enhancing incentives/rewards (see Conlin, Lynn \& O’Donoghue, 2003; Jacob \& Page, 1980).

In order for tipping to function as an incentive/reward for service, consumers must leave larger tips the better their evaluations of the service. ${ }^{1}$ One reason for expecting them to do this can be found in a psychological theory called "equity theory." This theory is similar to the norm of reciprocity in positing that people are socialized to put more into their relationships with others the more they get out of those relationships (Walster, Berscheid \& Walster, 1973). The theory suggests that consumers will feel some psychological pressure to leave larger tips the better the service they receive (Lynn \& Graves, 1996). Consistent with this theoretical prediction, researchers have found that the tip sizes left by restaurant patrons are positively and reliably, though weakly, related to their evaluations of service (see Lynn, 2001 and 2003, for reviews). However, existing research on the relationship between service ratings and tip sizes has used a between-subjects, correlational design (c.f., Lynn \& Grassman, 1990). This means that the observed relationships could be due to stable dispositional differences between tippers rather 
than to a direct causal impact of service on tipping. For example, consumers with a strong dispositional tendency toward gratitude may rate service more highly and give larger tips than do consumers with a weaker dispositional tendency toward gratitude even if both receive comparable service. If so, this would create a spurious correlation between service ratings and tip sizes. Dispositional gratitude is not alone in this regard; other stable dispositional differences between tippers in extraversion, friendliness, generosity, etc... could also create a spurious relationship between service ratings and tip size. The purpose of the current research is to help rule out these stable dispositional differences between tippers as confounds responsible for the positive correlation between service ratings and tip sizes.

Stable dispositional differences occur between individuals; it does not make sense to talk about stable dispositional differences within a single subject. This means that all stable dispositional differences between tippers can be eliminated as confounds of the service-tipping relationship by collecting multiple observations per subject and doing a within subjects analysis i.e, by statistically controlling for subjects/tippers. It is not necessary to identify, measure, and control for specific stable dispositions because as long as you control for the individual leaving the tip, you automatically control for all the stable dispositions that differentiate that individual from others in the sample. The present study provides such a within-subject assessment of the service-tipping relationship.

\section{METHOD}

Business students at a commuter college in a large southern city were asked to record information about each time they ate restaurant food over a four week period. Among the information recorded was the following: 
(1) meal [breakfast, lunch, supper, other - this variable was dummy coded into lunch $(y=1 / n=0)$ and breakfast/other $(\mathrm{y}=1 / \mathrm{n}=0)]$,

(2) dessert (whether or not the participant had a dessert: $y=1 / n=0$ ),

(3) bill (amount of the bill for the entire party not counting tip),

(4) contribution (the amount of the bill not counting tip that the participant was personally responsible for paying),

(5) type of visit (ate at the restaurant, take out, or delivery),

(6) group size (number of people in the dining party),

(7) courses (number of courses the participant had),

(8) alcohol (whether or not the participant had alcohol: $y=1 / n=0$ ),

(9) service (whether or not the restaurant had waiter/waitress service: $y=1 / n=0$ ),

(10) service quality [a single item rating of service on a five point scale (with $1=$ poor and $5=$ excellent) similar to that used by Bodvarsson \& Gibson, 1994; Bodvarsson, Lukstich \& McDermott, 2003; and Boyes, Mounts \& Sowell, 2004], and

(11) tip (dollar and cents amount that the participant left as a tip; this amount was divided by contribution to obtain a measure of tip percentage).

Dining occurrences were retained for analysis in this study if they involved: (i) eating in the restaurant, (ii) waiter/waitress service, (iii) non-zero contributions from the participant, and (iv) non-missing values for the other variables. In addition, data had to come from a participant providing at least two valid observations in order to be retained for analysis in this study. Finally, one observation with a $\$ 70$ tip was dropped from the analysis as an outlier -- the next largest tip was $\$ 15$. The cleaned data set contained information about 275 dining occurrences experienced 
by 51 participants. The number of observations (dining experiences) from each participant ranged from 2 to 24 with a mean of 5.39 and a standard deviation of 4.91 .

\section{RESULTS}

Subjects patronized a wide variety of restaurants, including Bennigans, Black Eyed Pea, Caraba's, Chili's, Denny's, Don Bravo Mexican, House of Pies, Houston's, IHOP, Landry's, Olive Garden, Pappasitos, Pizza Hut, Red Lobster, Rudy Lechners', TGI Friday, and 59 Diner. Forty-one percent of the meals recorded involved lunch, 31 percent involved alcohol consumption, and 16 percent involved dessert consumption. The number of people at the table ranged from 1 to 15 with a mean of 2.58 and a standard deviation of 1.55 . Their bill sizes ranged from $\$ 3.72$ to $\$ 197.00$ with a mean of $\$ 25.36$ and a standard deviation of $\$ 22.71$ and their tip sizes ranged from $\$ 0.20$ to $\$ 15.00$ with a mean of $\$ 2.99$ and a standard deviation of $\$ 2.47$.

Hierarchical linear modeling with restricted maximum likelihood estimation and robust standard errors was used to analyze the data. This involved estimation of two models -- a levelone (within subjects) model predicting percent tip from service quality, bill, contribution, group size, courses, dessert, alcohol, lunch, and breakfast/other; and a level-two model predicting both the intercept and the coefficient for service quality separately for each participant. The level-one model produced significant coefficients only for service quality $(B=2.06$; $\mathrm{t}(50)=2.57, \mathrm{p}<.02)$, contribution $(\mathrm{B}=-.050 ; \mathrm{t}(265)=-3.99, \mathrm{p}<.0001)$, and alcohol $(\mathrm{B}=6.34 ; \mathrm{t}(265)=2.88, \mathrm{p}<$ $.005){ }^{2}$ The negative effect of contribution (or personal bill size) and the positive effect of alcohol consumption replicate similar findings in the existing literature (see Lynn, 2006, for a review). Of particular interest, however, is the service quality effect, which indicated that, on 
average, participants tipped an extra two percent of the bill for each additional point they rated service on a five point scale. Tip sizes are related to service ratings in a within-subjects analysis, so the relationship is not attributable to stable dispositional differences between tippers.

Insert figure 1 about here

The level-two model indicated that the intercepts $\left(\chi^{2}(45)=62.45, \mathrm{p}<.05\right)$ and the coefficients for service quality $\left(\chi^{2}(45)=69.17, p<.05\right)$ varied significantly across participants. The specific values for the intercepts are not very meaningful, but they do indicate that there are indeed individual characteristics related to the amount that individuals tip. Of particular note for this paper, though, are the significant random effects for service quality. As already noted, tips increase two percentage points on average for each one point increase in service quality ratings. However, the specific relationship between service quality and tip percentage varied across subjects. As depicted in Figure 1, most participants increased their tips by one to two percent of the bill for each one point increase in service rating on a five point scale; however, many varied their tip percentages with service quality hardly at all, while others varied their tip percentages with service quality much more than the two point average. This variability in the tendency to base tips on service helps to explain why the service-tipping relationship is weaker than many expect - because the existence of people who do not tip as a reward dilutes the service-tipping relationship but probably not the expectations of a strong relationship among those who do tip as a reward. Interestingly, the participants' coefficients for service quality were significantly, positively correlated with their average tip percentages $(r=.70, n=51, p<.001)$, meaning that 
the more people varied their tip percentages with service quality, the larger the tip percentages they left on average. This finding is consistent with two recent studies finding that people's selfreported desire to tip as a reward for service is positively related to their tip sizes (Azar, 2008; Lynn, 2008).

\section{DISCUSSION}

One concern about the methodology of the current study is the fact that the measure of tip size was self-reported by tippers. As a reviewer pointed out, these reports may have been biased in order to make the tipper appear generous or to make tips more consistent with service ratings. However, it would be difficult to get repeated measures of the tip sizes left by a subject that were not self-reported. Furthermore, these impression management pressures are not unique to this study because much of the research in this area relies upon self-reported tip sizes (see Lynn \& McCall, 2000). Moreover, one study that tested for bias in self-reported tips found no evidence that they were inflated (Lynn \& Grassman, 1990). That finding together with the current replication of previous findings about the effects on tipping of bill size, alcohol consumption, and motivation to reward service supports the validity of the tip reports used in this study.

Another issue concerning the current methodology is its correlational nature, which does not allow strong causal inferences. However, ethical and practical considerations preclude randomly assigning restaurant patrons to receive good or bad service, so correlational research designs are the only way to assess service effects on tip sizes in naturalistic settings. ${ }^{3}$ As a result, existing field research on service-tipping relationship has relied on cross-sectional, between 
subjects correlational studies. The current within-subjects design improves upon that existing research by ruling out stable dispositional differences between tippers (such as differences in dispositional gratitude, extraversion, friendliness, generosity, etc...) as potential confounds of the correlation between service ratings and tip sizes. Thus, this study contributes to the tipping literature by increasing the evidence that service has a positive, causal impact on tip sizes.

Evidence supporting the causal impact of service on tip sizes is important for both theoretical and practical reasons. First, it speaks to the applicability of equity theory to marketplace exchanges between consumers and others. Although equity theory is well established (Walster, et. al., 1973), it is possible that different norms govern consumer-seller exchanges than govern the social and employer-employee exchanges that provide the context for most equity research. Supporting this possibility, one study has found that consumers' judgments of fairness are affected more by how much they get out of commercial exchanges than by how much the seller gets out of the exchange (Oliver \& Swann, 1989). Evidence that consumers voluntarily tip more in response to receiving good service indicates that they are not always exclusively concerned with how much they get out of a commercial exchange and suggests that equity norms may govern at least some consumer-seller exchanges.

Second, evidence supporting the effects of service on tip sizes provides indirect support for economic theory about the efficiency enhancing nature of tipping norms (Conlin, et. al., 2003; Jacob \& Page, 1980) and for managerial use of tipping as an employee control mechanism (Lynn 2001). In order for tipping to efficiently provide incentives/rewards for good service, servers must perceive a contingency between their service efforts and tip incomes and those perceptions logically require that consumers tip more in response to good service. While it has 
been argued that the relationship between tips and service is too weak to be noticed by servers and, therefore, that tipping is unlikely to provide an effective incentive/reward for good service (Azar, 2007; Lynn 2001, 2003, Lynn \& McCall, 2000), the current study found that the strength of the relationship varies considerably among consumers. It is possible that servers are able to perceive the relationship among those regular customers for whom it is strongest and, given the consistency of those strong service-tipping relationships with conventional expectations, generalize that relationship to all consumers. Ultimately, the impact of tipping on service levels is an empirical question that needs to be assessed directly. In the mean time, however, evidence that consumers do tip more in response to better service supports the possibility that tipping provides service enhancing incentives/rewards to waiters and waitresses.

\section{NOTE}

1. Tipping can function as an incentive/reward for up-selling without being related to service as long as consumers tip a percentage of their bills. However, this paper focuses on tipping as an incentive/reward for service.

2. A similar analysis using absolute tip amount rather than percent tip as the dependent measure produced essentially the same results.

3. Role playing studies can and have been used to experimentally study hypothetical service effects on hypothetical tipping decisions (e.g., Azar, 2008; Bodvarsson \& Gibson, 1999; Tse, 2003), but they have validity problems of their own (see Lynn, 2000). 


\section{REFERENCES}

Azar, O. H. (2007). Incentives and service quality in the restaurant industry: The tipping-service puzzle. Applied Economics, 1-11, iFirst.

Azar, O.H. (2008). Tipping motivations and behavior in the US and Israel. Journal of Applied Social Psychology, forthcoming.

Bodvarsson, O. \& Gibson, W. (1994). Gratuities and customer appraisal of service: Evidence from Minnesota restaurants. Journal of Socio-Economics, 23 (3), 287-302.

Bodvarsson, O. \& Gibson, W. (1999). An economic approach to tips and service quality: Results of a survey. The Social Science Journal, 36(1), 137-147.

Bodvasson, O. Lukstich, W.A. \& McDemott, S. (2003). Why do diners tip: Rule of thumb or valuation of service? Applied Economics, 35, 1659-1665.

Boyes, W., Mounts, W.S. \& Sowell, C. (2004). Monitoring and moral hazzard in restaurant tipping. Journal of Applied Social Psychology, 34(12), 2616-2628.

Conlin, M., Lynn, M. \& O'Donoghue, T. (2003). The norm of restaurant tipping. Journal of Economic Behavior and Organization, 52, 297-321.

Jacob, N. \& Page, A. (1980). Production, information costs and economic organization: The buyer monitoring case. American Economic Review, 70, 476-478.

Lynn, M. (2000). The relationship between tipping and service quality: A comment on Bodvarsson and Gibson's article. The Social Science Journal, 37, 131-135.

Lynn, M. (2001). Restaurant tipping and service quality: A tenuous relationship. Cornell Hotel and Restaurant Administration Quarterly, 42, 14-20.

Lynn, M. (2003). Tip levels and service: An update, extension and reconciliation. Cornell Hotel and Restaurant Administration Quarterly, 44, 139-148.

Lynn, M. (2006). Tipping in restaurants and around the globe: An interdisciplinary review. Chapter 31, pp. 626-643. In Mo. Altman (Ed.) Handbook of contemporary behavioral economics: Foundations and developments. Armonk, NY: M.E. Sharpe.

Lynn, M. (2008). Individual differences in self-attributed motives for tipping: Antecedents, consequences and implications. Unpublished manuscript, Cornell University, Ithaca, NY.

Lynn, M. \& Grassman, A. (1990). Restaurant tipping: An examination of three "rational" explanations. Journal of Economic Psychology, 11, 169-181. 
Lynn, M. \& Graves, J. (1996). Tipping: An incentive/reward for service? Hospitality Research Journal, 20, 1-14.

Lynn, M. \& McCall, M. (2000). Gratitude and gratuity: A meta-analysis of research on the service-tipping relationship. Journal of Socio-Economics, 29, 203-214.

Oliver, R.L. \& Swan, J.E. (1989). Consumer perceptions of interpersonal equity and satisfaction in transactions: A field study approach. Journal of Marketing, 53, 21-35.

Tse,A.C. (2003). Tipping behavior: A disconfirmation of expectation perspective. International Journal of Hospitality Management, 22, 461-467.

Walster, E., Berscheid, E. \& Walster, G.W. (1973). New directions in equity research. _Journal of Personality and Social Psychology, 25, 151-176. 
$-0 . \quad 27$

0. 1445899

1. 00011123445667789

2. 000000224478

3. 002679

4. $\quad 124478$

5. 1

FIGURE 1: Stem-and-leaf frequency distribution of the fifty-one participants' coefficients for service quality. 